\title{
Vitamin D status, calcium metabolism and linear growth parameters in exclusively breast fed term infants with and without supplementation of Vitamin D
}

\author{
S. N. Prashanth ${ }^{1}$, N. Rashmi², R. D. Suresh ${ }^{3}$ \\ ${ }^{1}$ Dr. Prashanth.S.N, Professor, ${ }^{2}$ Dr. Rashmi.N, Assistant Professor, ${ }^{3}$ Dr.Suresh R. D, Resident, all authors are affiliated \\ with Department of Pediatrics, JSS Medical College Hospital, JSS University, Mysuru, India.
}

Address for Correspondence: Dr. Rashmi.N, Department of Pediatrics, JSS Hospital, JSS University, M.G.Road, Mysuru, India.

\begin{abstract}
Objective: To compare the levels of vitamin D, calcium, phosphorus and alkaline phosphatase and linear growth parameters in exclusively breast fed term infants with and without supplementation of vitamin D. Design: Interventional study (Non Randomized). Setting: Department of Paediatrics and OBG in a Tertiary care Teaching Hospital, Mysuru. Participants: 60 term Healthy Neonates who were delivered in the hospital. In order to estimate the expected level with an allowable error of $20 \%$ and $95 \%$ confidence, the required sample size was considered to be a minimum of 28 for each group of only breast fed and breast fed with vitamin D supplementation. Thus we recruited 30 healthy term newborns for each group in our study. Main outcome measures: Study infants were divided into two groups, Group A-Only breast fed; Group B-breast fed with Vitamin D supplementation (800 IU/day for 4 months). The cord blood sample reports and linear growth parameters at birth with results at the end of 4th month+15days between the two groups were compared and statistical analysis was made. Results: This study showed significant improvement in vitamin D, calcium and phosphorus levels at the end of 4 months after supplementing daily 800 IU of vitamin D (cholecalciferol). However, there were no significant change in linear growth parameters between the two groups at the end of 4 months. Conclusion: This study shows the advantage of supplementing vitamin D to all infants at a relatively higher (800IU) but safe dose since birth in preventing rickets and complications of hypocalcemia.
\end{abstract}

Key words: Biochemical parameters, Exclusive breast feeding, Growth parameters, Vitamin D supplementation.

\section{Introduction}

There are global efforts to promote breastfeeding as optimal nutrition in early infancy. However, vitamin D deficiency and rickets among breast-fed infants who lack adequate sunlight exposure and do not receive vitamin D supplementation are increasingly being reported worldwide. Maternal vitamin D status and human milk vitamin D concentration significantly affect infant vitamin D status and, therefore, should be of global concern.

Vitamin D deficiency has emerged as a significant public health problem throughout the world. Even in the Indian context, it has been reported to be present in majority of children inspite of wide availability of

Manuscript received: $4^{\text {th }}$ August 2016

Reviewed: $14^{\text {th }}$ August 2016

Author Corrected; $25^{\text {th }}$ August 2016

Accepted for Publication: $12^{\text {th }}$ September 2016 sunlight. The manifestations of deficiency may vary from hypocalcemic seizures, tetany in infancy and adolescence to florid rickets in toddlers. So, routine supplementation starting from newborn period is being increasingly endorsed by various international organizations. Prevention by sensible sunlight exposure, food fortification and routine supplementation are the currently available options for tackling this nutritional deficiency.

Resurgence of prolonged exclusive breast feeding has led to a coincident increase in incidence $(28 \%$ in year $1990,50 \%$ in year 2000) of vitamin D deficiency in infancy [1]. Exclusive breast feeding with inadequate vitamin D supplementation in the baby was concluded to be the most important risk factor $[2,3,4]$. Vitamin D content of human milk is low $(20-60 \mathrm{IU} / \mathrm{L})$ even in 
vitamin D-replete mothers [5,6]. Total calcium absorption is generally lower in breast fed infants than in formula-fed infants [7]. Daily Vitamin D supplementation is usually considered to be the most appropriate way to prevent Vitamin D deficiency and thereby hypocalcaemic seizures and rickets in infancy [8].

\section{Methods}

Study Design: Interventional study (Non Randomized).

Sampling Method: Convenience sampling

Study Place: Department of and Paediatrics and Obstetrics, Tertiary care teaching Hospital, Mysore.

Study period: January 2015 to July 2015.

Source of data: Term healthy neonates who were delivered in a tertiary care hospital, Mysore. Sample size: 60 term healthy babies delivered in the hospital. Estimation of sample size was based on the expected mean and case standard deviation, reported by a Korean study. In order to estimate the expected level with an allowable error of $20 \%$ and $95 \%$ confidence, the required sample size was considered to be a minimum of 28 for each group of only breast fed and breast fed with vitamin D supplementation. Thus we recruited 30 healthy term newborns for each group in our study (Groups A and B). Those who were advised exclusive breastfeeding were considered as group A $(n=30)$. For group B $(n=30)$, 800 IU [9] of vitamin D was supplemented once daily from day-1 of life.

Term infants with any major health problems (excluding infant of diabetic mother, birth asphyxia, large for gestational age, polycythemia ), IUGR babies, babies diagnosed to have hypocalcaemia and those babies who had vitamin D less than $75 \mathrm{nmol} / \mathrm{L}$ at birth were excluded from the study.

Method of collection of data: After taking informed consent from parents, counselling for exclusive breast feeding was done and those who accepted for exclusive breast feeding, follow up and vitamin D supplementation, were considered for the study. Cord blood of $4 \mathrm{ml}$ was collected under strict aseptic precautions for analysis of serum concentrations of vitamin D (25OHD3-CLIA method), total calcium (Ca), inorganic phosphorus (P) and alkaline phosphatase (ALP).

Anthropometric measures like length, weight and head circumference were measured and interpreted according to WHO standards. Vitamin D 25(OH)D levels were interpreted according to the US endocrine society guidelines [10].

Total serum calcium level interpretation was done as follows [11].

\begin{tabular}{|c|c|}
\hline Total serum Calcium & $\mathrm{mg} / \mathrm{dl}$ \\
\hline Full Term Birth to 7 days & 8 to 10 \\
\hline 7 days to 1 year & 8.8 to 10.8 \\
\hline
\end{tabular}

For 60 infants of the study group, follow up dates were given at the age of 16-18 weeks. Babies were followed up regularly throughout the study period for compliance of vitamin D drops. Telephonic reminders were made close to follow up.

At end of 4 months (16 weeks+15days), $4 \mathrm{ml}$ of blood sample was drawn and re-evaluated serum concentrations of vitamin D (25OHD3-CLIA method), total calcium (Ca), inorganic phosphorus (P), alkaline phosphatase (ALP) and linear growth parameters were measured for both groups. The cord blood sample reports and linear growth parameters at birth with results at the end of 4 th month +15 days between the two groups were compared and interpretations were made.

Statistical Analysis: Made with SPSS windows (version 16.0). We assessed difference between two groups using chisquare test for categorical variables. Continuous variables were analysed by using student $t$ test and ANCOVA (Analysis of covariance) test. 


\section{Results}

Mean gestational age in Group A was 39 weeks 2 days and in Group B was 39 weeks. The non-significant p-value infers that the distribution of mean gestational age was similar in both groups. Distributions of sex in both groups were equal. There was no significant difference between the two groups in the baseline variables like birth weight, length and head circumference of babies before intervention.

The comparison of cord blood calcium, phosphorus, Alkaline phosphatase and Vitamin D levels between two groups at birth did not reveal any statistically significant difference. It was observed that the vitamin $\mathrm{D}$ level in only breast fed (Group A) infants was significantly low $(\mathrm{p}=0.040)$ at the end of 4 months compared to cord blood levels.

The levels of calcium and phosphorus in only breast fed (Group A) infants were significantly low ( $p=0.000)$ at the end of 4 months compared to cord blood, whereas alkaline phosphatase level was significantly high $(p=0.000)$ at the end of 4 months compared to cord blood. However, the Vitamin D level (mean 109.73) in vitamin D supplemented breast fed infants was significantly high $(\mathrm{p}=0.000)$ at the end of 4 months compared to cord blood (Table I).

Table I. Comparison of vitamin D levels between two groups at the end of 4 months

Group A: Only breast fed

Group B: Breast fed with Vitamin D supplementation

\begin{tabular}{|c|c|c|c|c|c|c|c|}
\hline Variable & Group A & & Group B & & $\begin{array}{l}\text { t- test } \\
\text { value }\end{array}$ & d.f & P-value \\
\hline & Mean & SD & Mean & SD & & & \\
\hline $\begin{array}{c}\text { Vitamin D } \\
\mathrm{nmol} / \mathrm{L}\end{array}$ & 94.17 & 12.214 & 109.73 & 7.129 & -6.029 & 58 & .000 \\
\hline
\end{tabular}

Comparison of anthropometric parameters (linear growth parameters) between the two groups at the end of 4 months is shown in Table II.

Table-II: Comparison of anthropometric (linear growth parameters) between two groups at the end of 4 months Group A: Only breast fed

Group B: Breast fed with Vitamin D supplementation.

\begin{tabular}{|c|c|c|c|c|c|c|c|}
\hline \multirow{2}{*}{ Variable } & \multicolumn{2}{|c|}{ Group A } & \multicolumn{2}{c|}{ Group B } & \multirow{2}{*}{$\begin{array}{c}\text { t- test } \\
\text { value }\end{array}$} & \multirow{2}{*}{ P-value } \\
\cline { 2 - 7 } & Mean & SD & Mean & SD & d.f. & \\
\hline Weight in $\mathrm{kg}$ & 6.43 & .5938 & 6.36 & .4178 & .528 & 58 & .599 \\
\hline Length of the baby in cm & 60.4366 & 9.9595 & 62.3200 & 2.2392 & -1.011 & 58 & .316 \\
\hline Head circumference in cm & 40.5633 & .9182 & 40.5733 & .6781 & -.048 & 58 & .962 \\
\hline
\end{tabular}

In our study we observed that in only breast fed infants the levels of calcium (8.7) and phosphorus (4.2) were significantly low $(\mathrm{p}=0.000)$ compared to vitamin $\mathrm{D}$ supplemented infants at the end of 4 months.

Whereas the level of alkaline phosphatase (316.70) was significantly low ( $\mathrm{p}=0.001)$ in vitamin D supplemented infants compared to only breast fed infants. (Table III).

To ensure whether this difference is really due to the interventions or due to the initial values, ANCOVA (Analysis of covariance) test was applied.

The mean values of the two groups were shown in figures instead of tables and at the end of the figures, ANCOVA test results were shown for each parameter separately. 
Table-III: Comparison of mean difference in levels of vitamin D, calcium, phosphorus and alkaline phosphatase between two groups at birth and at the end of 4 months

Group A: Only breast fed

Group B: Breast fed with Vitamin D supplementation

\begin{tabular}{|c|c|c|c|c|c|c|c|}
\hline Variable & Group A & Group B & & $\begin{array}{c}\text { t- test } \\
\text { value }\end{array}$ & d.f & P-value \\
\hline & $\begin{array}{c}\text { Mean(mean } \\
\text { difference) }\end{array}$ & SD & $\begin{array}{c}\text { Mean (mean } \\
\text { difference) }\end{array}$ & SD & & & \\
\hline Calcium & .8700 & .8424 & -.4767 & 1.7300 & 3.833 & 58 & .000 \\
\hline Phosphorus & .6567 & .5852 & .0100 & .4589 & 4.762 & 58 & .000 \\
\hline $\begin{array}{c}\text { Alkaline } \\
\text { phosphatase }\end{array}$ & -149.16 & 147.21 & -50.90 & 60.54 & -3.381 & 58 & .001 \\
\hline Vitamin D & 5.33 & & & & & & \\
\hline
\end{tabular}

The mean weight, length and head circumference of two groups at birth and at the end of 4 months after the intervention were analysed. It was found that the mean weight, length and head circumference at the end of 4 months were increased in both groups equally. The ANCOVA test results inferred that there were no significant differences in these parameters of the two groups even after controlling them at birth. This ensures that Vitamin D supplementation has no influence on increase in the body weight at the end of 4 months. However, weight at birth has high influence on weight gain at the end of 4 months. i.e., if infants have higher birth weight, more weight was expected at the end of 4 months and vice versa. The same principle would apply to length and head circumference also.

The results of the ANCOVA test inferred that Vitamin D supplementation has influence on the calcium, phosphorus and alkaline phosphatase levels at the end of the 4 months since there was a statistically significant difference between the two groups even after controlling their levels at birth. The same inference holds good for Vitamin D levels as well.

\section{Discussion}

Serum Vitamin D level was determined by 2 major factors, i.e., the dietary intake and production in the skin when exposed to the sun (ultraviolet B irradiation, UVB) [12]. Half-life of serum vitamin D is 12-20 days and healthy term infants are born with the storage of vitamin D enough for next couple of months.

Maternal influences on vitamin D status in the exclusively breastfed neonate is more pronounced during the first 2 months of life, but, thereafter, infant vitamin $\mathrm{D}$ status is more directly affected by sunshine exposure and vitamin D supplementation [13,14,15]. So, factors such as adequacy of sunlight exposure of mothers and infants, diet and vitamin D supplementation, and skin pigmentation should be considered as well as seasonal differences.

Human breast milk contains only 12-60 IU/L of vitamin $\mathrm{D}$ which is much less than the required maintenance amount. Hence all breast fed infants may show lower vitamin $\mathrm{D}$ status and bone mineralization than vitamin
D supplemented/formula fed infants. Measures to prevent vitamin D deficiency include increased skin exposure to sunlight, increased fortification of food items with vitamin $\mathrm{D}$, and vitamin $\mathrm{D}$ supplementation [16].

In our study, Vitamin D status, total serum calcium, phosphorus, alkaline phosphatase with weight, height and head circumference were considered and compared. 30 infants in each group participated in our 4 month study period. We defined vitamin D deficiency, insufficiency and sufficiency as $<50 \mathrm{nmol} / \mathrm{L}, 50$ to $75 \mathrm{nmol} / \mathrm{L}$ and $\geq 75 \mathrm{nmol} / \mathrm{L}$ respectively and hypocalcaemia as $<8 \mathrm{mg} / \mathrm{dl}$ at birth.

At birth there were no statistical significant differences among the two groups in both physiological and biochemical parameters. We supplemented 800 IU/Day [9] vitamin D in breast fed infants from day 1 of life. At the end of 4 months, calcium, phosphorus and vitamin D levels were significantly low and alkaline 
phosphatase was significantly high in exclusively breast fed term infants. However, there was no change in weight, length and head circumference at end of 4 months.

Gary M Chan.et.al [16] studied growth and mineralization of normal breast-fed infants with and without supplementation of vitamin D (400 IU daily) at various intervals $(n=51-22)$ infants only breast fed and 29 infants with vitamin D. They observed that bone mineral content was similar in both groups and also, lower $25-\mathrm{OH} \mathrm{D}$ value $(\mathrm{p}<0.05$, kruskal-wallis $)$ for human milk alone group at 4 months and higher alkaline phosphatase at 6 months $(p<0.05$,t test $)$ in human milk $+\mathrm{D}$ group.

In our study, we observed low calcium $(\mathrm{p}=0.000)$, phosphorus $(\mathrm{p}=0.000)$ and vitamin D level $(\mathrm{p}=0.000)$ with significantly high $(\mathrm{p}=0.001)$ alkaline phosphatase in only breast fed infants, compared with vitamin D supplemented (800 IU of Vitamin D/day) infants at the end of 4 months.

A study conducted by Mi-Jung KiM.et.al [17] on nutritional status of vitamin D and effect of vitamin D supplementation in Korean breast fed infants included a total of 74 newborns, divided into three groups -25 formula fed (Group A), 28 breast fed only (Group B), 21 with vitamin D supplementatiom (200IU/day from 2 months of age). There was no difference in anthropometric parameters among the three groups and mean vitamin D level and phosphatase levels were significantly low in exclusive breast fed infants. They also observed no difference in calcium and alkaline phosphatase among three groups.

However, our study showed significantly low calcium $(\mathrm{p}=0.000)$, phosphorus $(\mathrm{p}=0.000)$ and vitamin $\mathrm{D}$ level $(p=0.000)$ with high $(p=0.001)$ alkaline phosphatase in only breast fed, compared with vitamin D (800 IU) supplemented infants, even though there was no difference in anthropometric parameters between the two groups at end of 4 months.

Oya Halicioglu.et.al [18] in a cross sectional study for 1 year in 143 exclusively breast fed term infants who were supplemented with vitamin D 400IU/day started within 15 days of life, found vitamin $\mathrm{D}$ deficiency $(<50 \mathrm{nmol} / \mathrm{L})$ and issufficiency (51 to $74 \mathrm{nmol} / \mathrm{L})$ in $40(28 \%)$ and 55(38.5\%) respectively. Vitamin D was sufficient only in $48(33.6 \%)$ infants. They infered that despite 400IU/day of vitamin D supplementation in
Izmir, Turkey on winter days, the rate of vitamin D deficiency was high in 4-month old breast fed infants. So, there was a need to clarify optimal amount of vitamin D to be supplemented especailly in winter days.

Multiple studies from the US and Europe show that supplementation of breastfeeding infants with $400 \mathrm{IU} / \mathrm{d}$ of vitamin $\mathrm{D}$ is sufficient to prevent vitamin D deficiency when sun exposure is limited [19,20,21,22]. It is, therefore, recommended that all breastfeeding infants in North America and the United Kingdom receive $400 \mathrm{IU}$ of vitamin $\mathrm{D}$ supplement orally, assuming minimal sunlight exposure [23,24]. It is, however, unknown whether such intake is adequate in dark-skinned infants and in parts of the world, especially our country, where there is a high prevalence of severe vitamin D deficiency [25]. This supports our observation that with vitamin D supplementation of $800 \mathrm{IU} /$ day from day 1 of life (i.e; at a relatively higher dose), mean vitamin D level was $109.73 \mathrm{nmol} / \mathrm{L}$ and no vitamin $\mathrm{D}$ insufficiency ( 51 to $74 \mathrm{nmol} / \mathrm{L}$ ) at the end of 4 months. This probably indicates that Vitamin D supplementation in higher but a safe dose of 800 IU/day may prevent it's insufficiency and deficiency in all seasons and also in dark skinned infants.

Vandana Jain. et.al [26] found infants who were on vitamin D supplement at 3 months had significantly higher serum 25OHD [13.6(2.5-3.8)ng/ml] compared to those who were not $[8.6(2.5-27.5) \mathrm{ng} / \mathrm{ml}, \mathrm{p}=0.009]$. This was comparable to our study.

\section{Conclusion}

Our study showed improvement in vitamin D, calcium and phosphorus levels at the end of 4 months after supplementing daily 800IU of vitamin D (cholecalciferol), but, there were no significant changes in linear growth parameters between the two groups at end of 4 months. So, this shows the advantage of supplementing vitamin D at a higher (800IU/day) but safer dose to all infants since birth in preventing rickets and complications of hypocalcemia. However, there were a few limitations in our study that we had not measured maternal vitamin $\mathrm{D}$ level which is a predictor of infant 25(OH)D level, infant PTH level was not included to find secondary hyperparathyroidism in vitamin D insufficiency $(51-74 \mathrm{nmol} / \mathrm{L})$ infants and sunlight exposure, clothings and seasonal variations were not considered.

Contribution details: PSN: Guarantor, overall coordinator and revised the manuscript for intellectual 
content. NR: Conception, literature search, manuscript writing and critical revision. SRD: Concept, data acquisition, analysis and preparation of the manuscript.

Funding: Nil, Conflict of interest: Nil

Permission from IRB: Yes

\section{References}

1. Mother's survey, Ross Products Division, Abbot Laboratories. Breast feeding trends through 2000. Available at: http : // www. ross. com/ about Ross/ Survey.pdf.

2. Kreiter SR, Schwartz RP, Kirkman HN Jr, Charlton PA, Calikoglu AS, Davenport ML. Nutritional rickets in African American breast-fed infants. J Pediatr. 2000 Aug;137(2):153-7.

3. Salle BL, Glorieux FH, Lapillone A. Vitamin D status in breastfed term babies. Acta Paediatr. 1998 Jul; 87(7):726-7.

4. Greer FR. Vitamin D deficiency--it's more than rickets. J Pediatr. 2003 Oct;143(4):422-3.

5. Bhalala U, Desai M, Parekh P, Mokal R, Chheda B. Subclinical hypovitaminosis D among exclusively breastfed young infants. Indian Pediatr. 2007 Dec;44 (12):897-901.

6. Taylor JA, Geyer LJ, Feldman KW. Use of supplemental vitamin $\mathrm{d}$ among infants breastfed for prolonged periods. Pediatrics. 2010 Jan;125(1):105-11. doi: 10.1542/peds.2009-1195. Epub 2009 Nov 30.

7. Raman L, Rajalakshmi K, Krishnamachari KA, Sastry JG. Effect of calcium supplementation to undernourished mothers during pregnancy on the bone density of the bone density of the neonates. Am J Clin Nutr. 1978 Mar;31(3):466-9.

8. Stephens WP, Klimiuk PS, Berry JL, Mawer EB. Annual high-dose vitamin D prophylaxis in Asian immigrants. Lancet. 1981 Nov 28; 2 (8257) : 1199202.

9. Abrams SA. Dietary guidelines for calcium and vitamin D: a new era. Pediatrics. 2011 Mar;127(3):5668. doi: 10.1542/peds.2010-3576. Epub 2011 Feb 21.

10. Holick MF, Binkley NC, Bischoff-Ferrari HA, Gordon CM, Hanley DA, Heaney RP, et al. Evaluation, treatment and prevention of vitamin D deficiency: an Endocrine Society. Practice guideline. J. Clin Endocrinol Metab. 2011;96:1911-30.
11. Holick MF. High prevalence of vitamin D inadequacy and implications for health. Mayo Clin Proc. 2006 Mar;81(3):353-73.

12. Balasubramanian S, Ganesh R. Vitamin D deficiency in exclusively breast-fed infants. Indian J Med Res. 2008 Mar;127(3):250-5.

13. Henderson A. Vitamin D and the breastfed infant. J Obstet Gynecol Neonatal Nurs. 2005 May-Jun;34 (3): 367-72.

14. Holick MF, Chen TC. Vitamin D deficiency: a worldwide problem with health consequences. Am J Clin Nutr. 2008 Apr;87(4):1080S-6S.

15. Saadi HF, Nagelkerke N, Benedict S, Qazaq HS, Zilahi E, Mohamadiyeh MK, Al-Suhaili AI. Predictors and relationships of serum 25 hydroxyvitamin D concentration with bone turnover markers, bone mineral density, and vitamin D receptor genotype in Emirati women. Bone. 2006 Nov;39(5):1136-43. Epub 2006 Jun 30 .

16. Gary M Chan, MD , Charles C Roberts, MD ,David Folland, MD, and Richard Jackson,MD;Growth and bone mineralization of normal breast-fed infants ans the effects of lactation on maternal bone mineral status; The American Journal of Clinical Nutrition 36: SEPTEMBER 1982, pp 438-443. Printed in USA (C) 1982 American Society for Clinical Nutrition.

17. Kim $\mathrm{MJ}^{1}$, Na B, No SJ, Han HS, Jeong EH, Lee W, Han Y, Hyeun T. Nutritional status of vitamin D and the effect of vitamin D supplementation in Korean breast-fed infants. J Korean Med Sci. 2010 Jan; 25(1):83-9. doi: 10.3346/jkms.2010.25.1.83. Epub 2009 Dec 26.

18. Oya Halicioglu, MD,a Sumer Sutcuoglu, MD,a Feyza Koc, MD,b Omur Yildiz, MD,c Sezin A. Akman, MD, a and Sadik Aksit, MDb; Vitamin D Status of Exclusively Breastfed 4-Month-Old Infants Supplemented During Different Seasons; Pediatrics. Volume 130, Number 4, October 2012; e921-e927.

19. Wagner CL, Howard C, Hulsey TC, Lawrence RA, Taylor SN, Will H, Ebeling M, Hutson J, Hollis BW. Circulating 25-hydroxyvitamin $\mathrm{d}$ levels in fully breastfed infants on oral vitamin d supplementation. Int J Endocrinol. 2010;2010:235035. doi: 10.1155/2010 / 235035. Epub 2009 Dec 9.

20. Ala-Houhala M, Koskinen T, Parviainen MT, Visakorpi JK. 25-Hydroxyvitamin D and vitamin D in 
human milk: effects of supplementation and season. Am J Clin Nutr. 1988 Oct;48(4):1057-60.

21. Wagner CL, Hulsey TC, Fanning D, Ebeling M, Hollis BW. High-dose vitamin D3 supplementation in a cohort of breastfeeding mothers and their infants: a 6month follow-up pilot study. Breastfeed Med. 2006 Summer;1(2):59-70.

22. Ala-Houhala M, Koskinen T, Terho A, Koivula T, Visakorpi J. Maternal compared with infant vitamin D supplementation. Arch Dis Child. 1986 Dec;61 (12):1159-63.

23. Institute of Medicine. Dietary reference intakes for calcium and vitamin D. Washington, DC: The National Academies Press; 2011.
24. Shaw NJ, Pal BR. Vitamin D deficiency in UK Asian families: activating a new concern. Arch Dis Child. 2002 Mar;86(3):147-9.

25. Saadi HF, Dawodu A, Afandi B, Zayed R, Benedict $\mathrm{S}$, Nagelkerke N,Hollis BW. Effect of combined maternal and infant vitamin D supplementation on vitamin D status of exclusively breastfed infants. Matern Child Nutr. 2009;5:25-32.

26. Vandana Jain, Nandita Gupta, Mani Kalaivani, Anurag Jain, Aditi Sinha \& Ramesh Agarwal. Vitamin D deficiency in healthy breastfed term infants at 3 months \& their mothers in India: Seasonal variation \& determinants; Indian J Med Res. 2011 Mar; 133(3): 267-273.

\section{How to cite this article?}

S. N. Prashanth, N. Rashmi, R. D. Suresh. Vitamin D status, calcium metabolism and linear growth parameters in exclusively breast fed term infants with and without supplementation of Vitamin D. Int J Pediatr Res.2016;3(9):661667.doi:10.17511/ijpr.2016.i09.06. 